\title{
O olhar de cada um: elementos sobre a construção cotidiana do Programa Saúde na Escola no DF.
}

\author{
Approaching the Brazilian Health and Education Program:the perspective of \\ managers and professionals in Federal District -DF.
}

La visión de cada un: elementos sobre la construcción cotidiana en el Programa de la Salud en la Escuela del DF.

Luciana Sepúlveda KÖPTCKE ${ }^{1}$ Izabela Amaral CAIXETA ${ }^{2}$

Fernando Gomes da ROCHA ${ }^{3}$

RESUMO: O artigo apresenta os achados referentes à institucionalidade e aos processos de implementação do Programa Saúde na Escola, em duas regiões do DF: Gama e Candangolândia. Tratou-se de pesquisa analítica de abordagem qualitativa que visou compreender as relações intersetoriais a partir da percepção dos atores envolvidos. Utilizou a análise de conteúdo de 15 entrevistas realizadas, em 2014, junto a gestores e profissionais dos setores saúde e educação, nas esferas federal distrital e local. Foram apresentados quatro temas estruturantes das falas dos entrevistados: a percepção do programa e de seus componentes; a percepção do papel que (seu setor) desempenha no PSE; a percepção sobre o papel ou atribuições do "Outro" e sobre a importância do Grupo de Trabalho Intersetorial. Revelou que a compreensão sobre o programa e seus componentes varia segundo o setor e a esfera de origem do entrevistado. O programa é percebido de forma positiva por potencializar articulação intrasetorial, embora enfrente desafios comunicacionais e na distribuição de poder entre os setores e esferas. A relação de afinidade entre o programa e a ação finalística de um setor é fator facilitador para a implementação do programa. Ratificou, ainda, a importância do reconhecimento de novos espaços de interlocução como os Grupos de Trabalho Intersetoriais para apoiar o trabalho intersetorial.

Palavras-chave: Saúde escolar; Ação Intersetorial; Promoção da Saúde.

\begin{abstract}
This study addresses health and education intersectoral actions adopted by Brazilian Health and Education Program (Programa Saúde na Escola, PSE). It aims at understanding the processes of intersectoral planning and decision making and of creating or adjusting practices, regarding the daily development of the program in Federal District (Distrito Federal, DF). To understand processes and contexts, 15 semi structured interviews were undertaken with managers and local professionals from both health and education sectors, at federal, district and local levels, in

\footnotetext{
${ }^{1}$ Pesquisadora da Fundação Oswaldo Cruz em Brasília, coordenadora do grupo e pesquisa Educação, Cultura e Saúde, Programa Educação, Cultura e Saúde. Fiocruz-Brasília. E-mail:lucianasepko@gmail.com

${ }^{2}$ Graduada em Sociologia pela Universidade de Brasília, professora da Secretaria de Educação do DF, membro do grupo de pesquisa Educação, Cultura e Saúde, Programa Educação, Cultura e Saúde. Fiocruz-Brasília.

${ }^{3}$ Possui graduação em Serviço Social pela Universidade Católica de Brasília, , membro do grupo de pesquisa Educação, Cultura e Saúde, Programa Educação, Cultura e Saúde. Fiocruz-Brasília.
} 
2014. The technique of content analysis proposed by Bardin was used to process data. Four major themes were unfolded: general program perception and program's components understanding; responsibilities and role in the program perceived; partners (from other level or sector) role and responsibilities perception; and participation in the program governance spaces. The study revealed that perception and program understanding varies according to sector and level (federal, district, local) of participant. Also, that PSE is generally well perceived by most interviewees, for it fosters intra sectoral dialog and interaction. However, challenges were presented as power asymmetry relations between sectors and levels. Aspects as consistent perception of the program's relation to the organization's mission and the importance of external partners and social networking were found to sustain program implementation. Finally, it stressed the importance of formally structured dialogical spaces as the Intersectoral Working Group (Grupo de Trabalho Intersetorial, GTI) to support cooperative planning and working between partners.

Key words: School Health, Intersectoral Action, Health Promotion.

RESUMEN: El artículo encontrado referente la institucionalidad y a los procesos de implantación del Programa de Salud en la Escuela, en dos regiones del DF, Gama y Candangolândia. Trata de investigación analítica de enfoque cualitativa que tiene como objetivo entender las relaciones intersectoriales de la percepción de los actores involucrados. Utilizado el análisis de contenido de 15 entrevistas hechas, en 2014, junto con directivos y profesionales de sectores de la salud y educación, en las esferas federal distrital y local. Fueron presentados cuatro temas estructuración de los discursos de los entrevistados: la percepción del programa y de sus componentes; la precepción del papel que (su sector) desempeña en el PSE, la percepción sobre el papel o atribuciones del "Otro" y sobre la importancia del Grupo de Trabajo Intersectorial. Reveló que la comprensión del programa y sus componentes esto varía de acuerdo con el sector de las esfera de origen del entrevistado. El programa es visto de forma positiva por potencializar articulaciones intersectoriales, aunque enfrenta desafíos comunicacionales y en la distribución de poder entre los sectores y esferas. La relación de afinidad entre el programa y la acción finalística de un sector es el factor facilitador para la implementación del programa. Afirmo mientras tanto la importancia del reconocimiento de nuevos espacios de interlocución como los Grupos de Trabajo Intersectoriales para apoyar el trabajo intersectorial.

Palabras- llave: Salud Escolar, Acción Intersectorial, Promoción de la salud

\section{INTRODUÇÃO}

A partir dos anos 80, observa-se a construção de outro paradigma para as ações de saúde na escola, em decorrência do movimento da reforma sanitária e das Conferências internacionais de Promoção da Saúde (1). Entretanto, foi apenas em 2007 que um programa de saúde na escola foi proposto conjuntamente pelos Ministérios da Saúde e da Educação, pelo Decreto Presidencial $n^{\circ}$ 6.286. O Programa Saúde na Escola veio corroborar com o fortalecimento da relação entre as redes da educação e da saúde, na sequência de experiências como o programa Saúde e Prevenção 
nas Escolas (SPE), a partir de 2003, (Brasília, 2008) e a criação da Câmara Intersetorial Educação e Saúde, Portaria Interministerial no 749, de 13/05/2005.

O PSE propôs articular de forma permanente e dinâmica as equipes de saúde da família e as comunidades escolares. O Programa deveria promover, ainda, a participação da sociedade civil, visando contribuir para a formação integral de estudantes de ensino básico público, por meio de ações de promoção, prevenção e atenção, estruturadas em quatro componentes: avaliação das condições de saúde das crianças, adolescentes e jovens; ações de promoção da saúde e de atividades de prevenção; educação permanente e capacitação dos profissionais da educação e da saúde e de jovens; monitoramento e avaliação.

No entanto, a relação entre a saúde e a educação nem sempre é harmoniosa. A parceria entre os Ministérios da Saúde e da Educação parece não funcionar de forma equânime. Existem contradições referentes à partilha de poder entre os setores na distribuição de responsabilidades nos espaços de governança, no financiamento das ações do programa e na centralização do processo de adesão dos municípios, todos protagonizados pelo setor saúde (2). Na esfera das práticas cotidianas, os professores "se queixam de que o setor saúde usa a escola e abusa do tempo disponível com ações isoladas (...)” (3).

Silva apontou desafios para o desenvolvimento do PSE proposto pelo Governo Federal, nos diferentes municípios, como o respeito à autonomia de gestão (4). A falta de coordenação e integração entre gestores e profissionais acarretam a burocratização dos serviços, o desperdício de tempo e de recursos humanos e financeiros e a duplicidade de ações (5).

No sentido de colaborar para a compreensão e o enfrentamento dos desafios da gestão intersetorial acima elencados, o presente estudo propõe identificar a situação da institucionalidade do PSE e compreender os processos de implementação do programa na escola, a partir da percepção dos atores envolvidos. Pretende-se aprofundar a situação particular do DF, em duas regiões, Gama e Candangolândia, onde se mesclam lógicas de estado e de município na gestão distrital. Presume-se que o processo de implantação no Distrito Federal reuniria, com maior facilidade, gestores das três esferas e de ambos os setores, apresentando um terreno dinâmico e intenso para a observação da articulação intersetorial.

A investigação da situação de articulação intersetorial do Programa Saúde na Escola e do seu grau de institucionalidade faz parte da pesquisa multicêntrica "Participação e dinamização juvenil no PSE: Projeto de Implementação e Acompanhamento das estratégias para educação entre pares do componente 02", coordenada pelo Programa de educação, Cultura e Saúde da Fiocruz de Brasília com apoio do FNDE, MEC, por meio de Termo de Cooperação $17033^{\mathrm{i}}$, em execução entre 2012 e 2015 em cinco UF.

Para efeito da análise aqui proposta, considera-se intersetorialidade como a relação que ocorre entre os diferentes setores- saúde, educação, ou outros, em dada esfera do governo bem como entre os diferentes níveis ou esferas, nacional, estadual e municipal. Observa também as ações 
propostas e compartilhadas com outras instâncias além das governamentais, como as universidades, empresas e organizações não governamentais (4).

O grau de institucionalidade problematiza os processos de adesão, o funcionamento dos espaços de governança do programa, em particular o Grupo de Trabalho Intersetorial e a existência de dispositivos de institucionalidade, como, por exemplo, a publicação de portaria instituindo o GTI nos níveis estadual, distrital e municipal, a designação de um coordenador local/setorial ou a existência de uma equipe intersetorial atuando na comunidade. A instituição pode ser definida como "norma universal", (a exemplo do casamento, da educação, a ideia do lucro); como formas sociais visíveis dotadas de organização jurídica ou material, a exemplo de uma empresa, uma escola, o sistema de saúde de um país; mas também como a experiência singular destas estruturas vivenciada pelos sujeitos, caracterizando o processo de simbolização e atualização das instituições na vida cotidiana (6). O PSE prevê os seguintes espaços de governança: CIESE (Portaria interministerial $n^{\circ} 675$, de 4 de junho de 2008; e os Grupos de Trabalho Intersetoriais: GTI federal e GTI municipal, (Decreto 6.286, de 5 de dezembro de 2007 e a Portaria $n^{\circ} 3.696$, de 25 de novembro de 2010 referente ao GTI estadual.

Finalmente, entende-se o programa a partir da observação das atividades e processos em curso, enfatizando a capacidade reflexiva dos agentes na adequação de uma proposta (programa) à realidade local. $\mathrm{O}$ foco é nas relações de interdependência entre eventos, onde a percepção dos atores constitui um dos eventos chave para compreender as práticas (7). Neste sentido, interrogase sobre como os atores das esferas federal, distrital e local percebem o Programa e seus componentes? Como percebem seu papel e aquele das outras esferas e setores no programa? Como percebem e participam das estruturas ou espaços formais e informais de planejamento e acompanhamento do Programa? Qual a relação entre as percepções dos papeis entre os diversos atores do PSE com as atribuições previstas no desenho original do programa?

\section{METODOLOGIA}

“A resposta certa, não importa nada: o essencial é que as perguntas estejam certas".

Mario

Quintana

Tratou-se de um estudo analítico, descritivo com abordagem qualitativa. A tarefa principal das ciências sociais, nesta perspectiva, consiste na compreensão da realidade humana vivida socialmente (8). Com o propósito de acessar as percepções dos atores envolvidos no PSE sobre seus componentes, seu papel e aquele de atores das outras esferas e setores, compreender como o programa tem sido apropriado nos diferentes arranjos institucionais da Educação e da Saúde, identificar a existência e o funcionamento das estruturas e espaços formais e informais de planejamento e acompanhamento das ações do Programa, foram realizadas 15 (quinze) entrevistas com profissionais da educação e da saúde no Distrito Federal. 
Dos quinze profissionais entrevistados, doze são mulheres. Na esfera federal foram entrevistadas duas técnicas consultoras do Ministério da Saúde; no âmbito distrital a gerente da Gerencia de Infra Estrutura e Apoio Educacional-GIAI da Secretaria de Educação do DF e a coordenadora do Núcleo de Saúde do Adolescente - NUSAD, da Secretaria de Saúde do DF. Na região da Candangolândia foram entrevistados: diretora, vice-diretor, um supervisor pedagógico e duas orientadoras educacionais do CEM JK Candangolândia, bem como a gestora do centro de saúde e a assistente social do Centro de Saúde $N^{\circ} 01$ do território. Na região do Gama foram: Diretor e professora do CEM 03 Gama, profissional da educação lotada na Coordenação Regional de ensino, enfermeira do Centro de Saúde Distrito de Divisas e Obras- DVO e enfermeira da Equipe de Saúde da Família da Regional de Saúde do território.

A amostra constituída foi intencional, considerando que os sujeitos da pesquisa deveriam representar os diferentes níveis da gestão e da atuação profissional no PSE (9), no DF. Utilizou o método de amostragem em bola de neve. A amostra caracteriza-se como não probabilística e inicia com a identificação de participantes que indicam novos participantes e assim sucessivamente até que seja alcançado o 'ponto de saturação' (10).

Desta forma, a amostragem em bola de neve, a snowball, utiliza a referência em cadeia. Os profissionais entrevistados para a presente pesquisa atuavam na esfera federal, Ministério da Saúde ${ }^{\mathrm{ii}}$, nas Secretarias de Educação e Secretaria de Saúde do Distrito Federal e também nas regiões administrativas do Gama e da Candangolândia por fazerem parte do Projeto.

Foram considerados conhecimentos prévios sobre a população pesquisada por parte dos pesquisadores envolvidos. As primeiras profissionais a serem entrevistadas foram identificadas no espaço do chamado Grupo de Fortalecimento da Ação Intersetorial - GFAI, estabelecido em 2012, como desdobramento de colaboração entre a Fiocruz Brasília e os atores do PSE. Reunia gestores e profissionais da educação e da saúde com o intuito de discutir estratégias e projetos em curso no

PSE distrital, nas regionais do DF e na esfera federal ${ }^{\mathrm{ii} 1}$.

A pesquisa seguiu as seguintes etapas:

- Revisão bibliográfica: foi realizado um levantamento preliminar a partir da base Scielo com os descritores: Intersetorialidade, institucionalidade, promoção da saúde, Saúde e Prevenção nas Escolas - SPE, Programa Saúde na Escola-PSE. Foram inicialmente priorizados estudos com foco na gestão intersetorial do PSE.

- Entrevistas Semiestruturadas: foram realizadas 15 entrevistas com roteiro semiestruturado em blocos sobre: trajetória profissional, relação com o PSE, percepção sobre local de atuação, percepção sobre a relação com outros setores, bem como sobre o próprio trabalho. 
Com relação ao tratamento dos dados, o material resultante das entrevistas foi transcrito e submetido à análise de conteúdo, iniciada pela chamada "leitura flutuante" (11). Após leitura preliminar, os dados foram analisados de forma a extrair os núcleos de sentido passíveis de constituir as unidades de análise, seja, os temas e subtemas identificados. Foram elencados seis temas dentre os quais quatro serão objeto de análise neste artigo: a) percepção do papel desempenhado no programa; b) percepção global do programa e de seus componentes; c) percepção sobre o outro setor ou esfera ${ }^{\text {iv }}$ e d) sobre a importância do Grupo de Trabalho Intersetorial. Foi, em alguns casos, verificada a frequência dos diferentes temas identificados. A interpretação do material considerou como variáveis externas a posição ocupada pelo sujeito no projeto- setor e esfera ${ }^{\mathrm{v}}$.

Para facilitar a leitura dos gráficos e tabelas, determinou-se legendas a partir da abreviatura usual de algumas expressões mais usualmente utilizadas.

São elas: AB: Atenção Básica; CS: Centro de Saúde; DE: Distrital Educação; DS: Distrital Saúde; FS: Federal Saúde; GEL: Gestor Educação Local e GRIAE: Gerência Regional de Infra estrutura e Apoio Educacional. Também se utilizaram as seguintes abreviaturas: GSL: Gestor Saúde Local; MS: Ministério da Saúde; PSL: Profissional Saúde Local; PROVAB: Programa de Valorização do profissional da Atenção Básica

A pesquisa foi aprovada pelo Comitê de Ética em Pesquisa-CEP do Instituto Oswaldo Cruz (IOC), Processo: 25194914.6.1001.5248, Parecer: 625.345.

\section{RESULTADOS}

A partir da fala das profissionais entrevistadas, a maioria relata ter experiência em suas trajetórias profissionais com ações de interface saúde, educação e juventude, como o Programa Bolsa Família ou Saúde e Prevenção nas Escolas-SPE, principalmente por sentir afinidade com as temáticas. Fator este que segundo as mesmas, facilita no exercício de seus cargos, mas ressaltam o desafio da comunicação entre setores, diferença de concepção das práticas intersetoriais e descontinuidade das ações após mudanças de governo.

Foram identificados temas centrais referentes à institucionalidade do programa, discutidos abaixo.

\section{Como os atores percebem o Programa?}

O tema "Percepção sobre o programa" foi organizado em três subcategorias de análise 1.1) Percepção global da situação do Programa segundo o local institucional dos profissionais entrevistados, considerando suas esferas de atuação e setor; 1.2) Percepção sobre os componentes do programa e 1.3) Percepção e participação nos espaços de governança do PSE.

\subsection{Percepção global da situação do Programa segundo o local institucional}


A percepção da situação do Programa em seu local institucional trata da forma como os profissionais entendem o programa a partir da posição que nele ocupam formalmente - o local onde trabalham e as responsabilidades que lhes são atribuídas com relação à implementação do PSE. O local institucional corresponde aos diferentes setores e esferas onde o PSE foi implantado. No quadro 01, abaixo, encontram-se dispostas as principais impressões dos atores sobre o PSE.

Quadro 1 - Percepção da situação do Programa em seu local institucional

\begin{tabular}{|c|c|c|c|}
\hline Federal & Distrital Saúde & Distrital Educação & Regional Local \\
\hline $\begin{array}{l}\text { Avanço na gestão com } \\
\text { equipe exclusiva na AB; } \\
\text { (FS1) } \\
\text { PSE promove articulação } \\
\text { entre secretarias MS;(FS1) } \\
\text { Momento de avaliação e } \\
\text { redesenho.(FS2) } \\
\begin{array}{l}\text { Dificuldade } \\
\text { descentralizar as ações } \\
\text { (FS2) }\end{array}\end{array}$ & $\begin{array}{l}\text { PSE alinha ações entre } \\
\text { programas já existentes } \\
\text { na Secretaria;(DS1) } \\
\text { PSE promove ações } \\
\text { intrasetoriais conforme } \\
\text { agendas;(DS1) } \\
\text { Incongruência entre } \\
\text { adesão formal e ações } \\
\text { realizadas (DS1) }\end{array}$ & $\begin{array}{l}\text { PSE é área fim da } \\
\text { gerência;(DE1) } \\
\text { PSE movimenta a } \\
\text { gerência (DE1) } \\
\text { PSE é abrangente } \\
\text { demais! articula a } \\
\text { gerência internamente } \\
\text { (DE1) } \\
\text { Crise de identidade no } \\
\text { DF; (DE1) }\end{array}$ & $\begin{array}{l}\text { Trabalho solitário, euquipe, } \\
\text { (GSL1); } \\
\text { Planejamento setorial na } \\
\text { saúde é importante pois sair } \\
\text { do CS é muito difícil; (PSL1) } \\
\text { PSE assumido por toda a } \\
\text { equipe do CS, articulação } \\
\text { interna positiva; (PSL2) } \\
\text { PSE na GRIAE um equívoco: } \\
\text { setor exclusivo; (GEL2) }\end{array}$ \\
\hline
\end{tabular}

Fonte: Entrevistas aplicadas aos participantes do Programa Saúde na Escola.

Embora o Programa pareça usufruir de uma impressão global positiva, foram elencados alguns desafios. Fator positivo comum entre as falas em ambos os setores, das esferas federal e distrital, é a potencialidade de articulação do Programa, seja a nível intrasetorial, "articulando secretarias ou a própria gerência, internamente", ou entre diferentes setores, integrando ações de programas já existentes. Cabe, ainda, sinalizar a percepção de avanço na gestão e a perspectiva de um momento profícuo de reestruturação do programa entre os atores da esfera federal, a despeito do afastamento circunstancial do Ministério da Educação no momento da pesquisa. Os gestores e profissionais da"ponta" reconheciam a importância da intra e da intersetorialidade, apontando para a necessidade de criação de um setor exclusivo para o desenvolvimento das ações do Programa e considerando positiva a articulação interna, quando ocorre.

No pólo dos desafios do programa, os atores da esfera federal enfatizaram a dificuldade em descentralizar as ações entre os Estados e Municípios, e afirmaram que "para o GTI estadual é difícil acompanhar as ações em todos os municípios (...) (FS1). Já para a gestão distrital, a dificuldade percebida é a "incongruência entre a adesão formal e as ações de fato realizadas (...) houve dificuldade em algumas regionais por ter muitas escolas aderidas ao PSE mas poucas ações realizadas (...) também existem escolas que atuam enquanto PSE mas que não possuem o programa" (DS1). No nível local os desafios de operacionalidade enfatizaram a dificuldade de articular as demandas criadas pelo PSE com as demais atividades do serviço. 


\subsection{Percepção sobre os componentes do Programa}

O Programa Saúde na Escola se estrutura em quatro componentes. A compreensão de como estes são percebidos pelos profissionais nos diferentes setores e esferas traz elementos para que se possa atuar de forma mais efetiva na implementação dos mesmos. O quadro 02, abaixo, sintetiza as falas dos informantes com relação aos componentes do programa.

Quadro 2- Percepção sobre os componentes do Programa.

\begin{tabular}{|c|c|c|c|c|}
\hline Comp. 01 & Comp.02 & Comp.02 & Comp.03 & Comp. 04 \\
\hline $\begin{array}{c}\text { O mais } \\
\text { complicado, sem } \\
\text { educação; (FS1) e } \\
\text { (FS2) } \\
\text { PROVAB tornou } \\
\text { possível realizar } \\
\text { (DS1) (PSL3) } \\
\text { Consegue avançar } \\
\text { cada vez mais } \\
\text { (DS1) } \\
\text { É mais saúde, mas } \\
\text { todos têm que } \\
\text { estar juntos; (DS1) } \\
\text { (DE1) } \\
\text { O mais fácil (DE1) } \\
\text { A dificuldade é } \\
\text { envolver educação; } \\
\text { (DE1) }\end{array}$ & $\begin{array}{c}\text { O entendimento } \\
\text { é partilhado entre } \\
\text { saúde e educação } \\
\text { (FS2); } \\
\text { Acontece na } \\
\text { ponta a partir da } \\
\text { realidade local } \\
\text { (FS2); } \\
\text { SPE faz parte, } \\
\text { integra programas } \\
\text { anteriores; (DS1), } \\
\text { (PSL1) (PSL3), } \\
\text { (GEL3), (PEL2) } \\
\text { Apoio PROVAB, } \\
\text { (DS1) }\end{array}$ & $\begin{array}{c}\text { Linhas bem } \\
\text { trabalhadas; (DS1) } \\
\text { Recorre aos temas } \\
\text { de DST, drogas; } \\
\text { (DS1) } \\
\text { Voltado para a } \\
\text { educação (DE1) } \\
\text { É o espaço para } \\
\text { integrar com a } \\
\text { escola, no Plano } \\
\text { Político Pedagógico } \\
\text {-PPP }\end{array}$ & $\begin{array}{c}\text { Em consolidação } \\
\text { no cotidiano; (FS1), } \\
\text { (FS2) } \\
\text { Formação enquanto } \\
\text { reunião, de forma } \\
\text { livre; (DS1) (PEL1) } \\
\text { O mais trabalhado, } \\
\text { por demanda dos } \\
\text { profissionais; (DS1) } \\
\text { Oferta de vagas de } \\
\text { chefes de cadeira; } \\
\text { (DS1) } \\
\text { De formas distintas, } \\
\text { nas regionais; (DS1) }\end{array}$ & $\begin{array}{c}\text { Precisa } \\
\text { qualificar, não } \\
\text { sabe dizer se } \\
\text { PSE contribui } \\
\text { (FS2); }\end{array}$ \\
\hline
\end{tabular}

Fonte: Entrevistas aplicadas aos participantes do Programa Saúde na Escola.

O Componente I trata da avaliação das condições de saúde das crianças, adolescentes e jovens que estão na escola pública; incluindo: Avaliação Nutricional, Saúde Bucal, oftalmológica, auditiva, atualização Caderneta da Criança e detecção precoce da hipertensão arterial sistêmica, bem como avaliação Clínica e Psicossocial. Para os atores do setor saúde, na sua maioria, este seria o componente de mais 'fácil' realização. Cabe, entretanto, enfatizar que para os informantes do nível federal este é considerado o componente mais desafiador, pela dificuldade de envolver os profissionais da educação. Foi ressaltado, ainda, o papel positivo do Programa de Valorização da Atenção Básica-PROVAB na articulação entre os setores.

O Componente II consiste em ações de promoção da saúde e de atividades de prevenção que incluem ações de Segurança Alimentar e Promoção da Alimentação Saudável, promoção das Práticas Corporais e Atividade Física nas Escolas, Educação para a Saúde Sexual, Saúde Reprodutiva e Prevenção das DST/AIDS (Saúde e Prevenção nas Escolas), Prevenção ao Uso de Álcool, Tabaco e Outras Drogas e Promoção da Cultura de Paz e Prevenção das Violências. Este foi o mais citado dentre os quatro componentes. Observa-se que a demanda do território surge como norteadora das práticas integradas entre saúde e educação. Novamente o PROVAB se destaca para a realização deste 
componente. Enquanto o componente I é entendido como uma ação da saúde, o componente II é entendido como ação inerente ao setor educação, voltando-se para as temáticas consideradas mais solicitadas pelos atores do espaço escolar, como a prevenção às DST’s e ao uso de drogas.

O Componente III refere-se à educação permanente e à capacitação dos profissionais da educação e da saúde e de jovens; este, segundo os profissionais entrevistados, ocorre na prática das atividades de trabalho do dia a dia, com alta demanda por parte dos mesmos.

Finalmente, o Componente IV concerne às ações de Monitoramento e Avaliação da Saúde dos Estudantes, com a realização de estudos para monitoramento e avaliação da situação de Saúde dos Estudantes; Pesquisa Nacional de Saúde do Escolar (PeNSE). Apareceu pouco na fala dos participantes, tendo sido colocado como um componente a se desenvolver e qualificar.

De modo geral, foi percebido que os componentes não são compreendidos ou mesmo conhecidos por todos, principalmente pelos atores da educação. Também é possível perceber que há maior identificação dos setores e facilidade de trabalhar com aqueles componentes que correspondem às atividades familiares a seu campo setorial, dificultando uma compreensão integral do PSE. Observa-se que o componente de formação é mais citado pelos profissionais da gestão distrital enquanto a demanda por formação aparece na fala de profissionais locais.

\section{3- Percepção sobre a importância do Grupo de Trabalho Intersetorial.}

O Decreto $n^{\circ} 6.286$ apontou a importância da descentralização e do respeito à autonomia federativa bem como da intersetorialidade como diretrizes do PSE. Neste sentido, foi instituído o Grupo de Trabalho Intersetorial nos níveis federal, municipal e posteriormente estadual (Portaria 1.861 de 4 de setembro de 2008; Portaria 3.696, de 25 de novembro de 2010). O Grupo de Trabalho Intersetorial é o espaço de governança previsto em todos os níveis do programa, cuja composição inclui obrigatoriamente representantes dos setores da saúde e da educação. Além destes, de caráter mandatório, o GTI pode convidar e sensibilizar outros participantes do governo, da sociedade civil organizada ou universidades a participar e integrar o grupo. Sua formalização se dá por meio de portaria federal, estadual, distrital ou municipal. Suas competências incluem: elaborar o projeto do PSE; elaborar o termo de adesão ao programa; articular e apoiar a implementação das ações do programa no território de responsabilidade e atuar no monitoramento das ações acompanhando o preenchimento dos instrumentos disponíveis, Sistema de Cadastro Nacional de Estabelecimentos da Saúde (SCNES) e Sistema Integrado de Monitoramento do MEC, (SIMEC).

A percepção sobre os Grupos de Trabalho Intersetorial foi múltipla, e variou bastante segundo a posição ocupada no programa. Atores da gestão federal apontaram a natureza e as atribuições do

GTI; aqueles do DF versaram sobre sua importância e sobre os desafios de seu funcionamento e aqueles próximos à base, que operam no cotidiano do programa, tenderam a desconhecer a existência 
do GTI distrital ou de qualquer outro tipo de reunião informal e intersetorial com o propósito de apoiar as ações do programa. Foram elencados os seguintes subtemas relativos aos GTI:

1- Papel técnico do GTI (federal): "Dar apoio técnico ao estado" (FS1);

2- O GTI apresenta arranjos diferentes nos Estados: "Cada GTI (estadual) se organiza de uma forma, onde cada Estado possui uma lógica própria e que estão em momentos de organização diferentes, a depender de cada equipe, de cada contexto" (FS1).

3- O GTI busca diálogo e descentralizar: “(...) muito desse diálogo se dá com os GTI’s, via regionais da saúde e da educação; então além de centralizar no Estado, ele passa numa regional para chegar no município" (FS2).

4- Importância da formalização do GTI (distrital): “ O GTI não está! Desde 2013 nós já começamos a ter vários problemas dentro do GTI. O fato de não termos o PSE institucionalizado de fato aqui, uma portaria que institucionalize o GTI, isso dificulta" (DS1); " a informalidade gera altos e baixos da adesão; descontinuidade da participação" (DS1); “(o GTI) é um espaço informal, faz a gestão central do programa e ramificação nas regionais (...) isso ainda não foi estabelecido legalmente" (DE1);

5- GTI (distrital) sofre com a instabilidade política: “(...) o Secretário de educação mudou de três a quatro vezes em um ano, o que atrapalhou muito as atividades. Na saúde houve uma ou duas mudanças (...)" (DS1).

6- Composição do GTI, por vários setores: “ Os GTI têm que ser compostos por vários setores, da saúde, da educação, a sociedade civil, adolescentes, jovens, universidade (...) isso assim que seria legal, era assim que a gente trabalhava na lógica do SPE e foi assim que a gente quis trazer” (DS1); “(...) as ações são fragmentadas em relação aos ciclos de vida, então quando a gente fala da representação da saúde, aí você chama muito mais segmentos da secretaria de saúde que precisam se envolver porque o PSE agora pega da creche ao EJA (...) tem que ter a representação dessas pessoas para um GTI articulado" (DE1);

7- Desconhecimento do GTI (ator local): “ Desconheço! Não participa, não é chamada e nem sabe quando e como vem acontecendo. Não há mobilização (...) Não nega a importância, mas de fato, não se sabe quem são as pessoas (...) isso de fato não existe " (GSL1); “desconhecia o GTI ou qualquer outro grupo de caráter intersetorial do PSE” (PSL2); “ (...) só conheceu o GTI esse ano" (GEL2).

\section{Como os atores percebem o seu papel no Programa?}

Muitas das dificuldades de atuação entre setores e esferas diferentes provêm da pouca clareza que cada parceiro tem do seu papel e do papel do Outro com quem trabalha. O quadro abaixo apresenta a percepção que os profissionais têm de seu papel no programa, segundo a esfera de sua atuação (federal, distrital ou local) 
Quadro 3- Percepções dos Atores sobre o seu papel no Programa

\begin{tabular}{|c|c|c|}
\hline Federal & Distrital & Local Regional \\
\hline \multirow{5}{*}{$\begin{array}{l}\text { Acompanha ações, articula } \\
\text { intersetorialmente,(FS1) } \\
\text { Reafirma princípios } \\
\text { conceitos; (FS2) } \\
\text { Expertise técnica (FS1) } \\
\text { Fomenta, dá insumos (FS2) }\end{array}$} & Implanta, $\quad$ resgata & Porta de entrada do sistema (GSL1) \\
\hline & anteriores (DS1) & Coordena as ações (GSL1) \\
\hline & $\begin{array}{lll}\text { Apresenta } & \text { como funciona } \\
\text { PSE;(DS1) } & & \\
\end{array}$ & Acompanha as ações (GSL1) \\
\hline & Mobiliza parceiros para responder & Planeja, monitora, avalia (GSL1) \\
\hline & demandas da escola;(DS1) & Atende e da aconselhamento (GSL1) \\
\hline Divulga ofertas (FS2) & $\begin{array}{l}\text { Institucionaliza e empodera } \\
\text { para atuar na ponta (DS1) }\end{array}$ & $\begin{array}{l}\text { Encaminha crianças para a escola } \\
\text { (GSL1) }\end{array}$ \\
\hline & $\begin{array}{l}\text { Articula intrasetorialmente (DE1) } \\
\text { Provê Infraestrutura e planeja com a } \\
\text { saúde (DE1) }\end{array}$ & $\begin{array}{l}\text { Busca o adolescente, novo papel para } \\
\text { a AP (GSL2) Direção dá suporte, } \\
\text { recursos (GEL3) }\end{array}$ \\
\hline & $\begin{array}{l}\text { Não tem competência para } \\
\text { estabelecer o PSE dentro do PPP } \\
\text { (DE1) }\end{array}$ & $\begin{array}{lcl}\text { GREB } & \text { pode } & \text { disponibilizar } \\
\text { coordenador(GEL2) }\end{array}$ \\
\hline
\end{tabular}

Fonte: Entrevistas aplicadas aos participantes do Programa Saúde na Escola.

Dentre os atores da saúde, destaca-se que as esferas federal e distrital apontaram a relação com a "ponta" como uma de suas atribuições, no entanto, na esfera local os profissionais se percebem mais como executores e não apontam a relação com as esferas superiores como parte de sua atuação. Isso pode refletir uma organização hierárquica com pouco fluxo da base (ponta) para o topo (gestão) dentro dos setores e dentro do próprio programa.

\subsection{Como os atores da saúde percebem o Outro setor ou esfera no Programa?}

O quadro abaixo apresenta a percepção que o setor saúde tem em relação à educação e entre as esferas do PSE na Saúde 
Quadro 4- Percepções dos atores da saúde sobre o Outro setor ou esfera no Programa

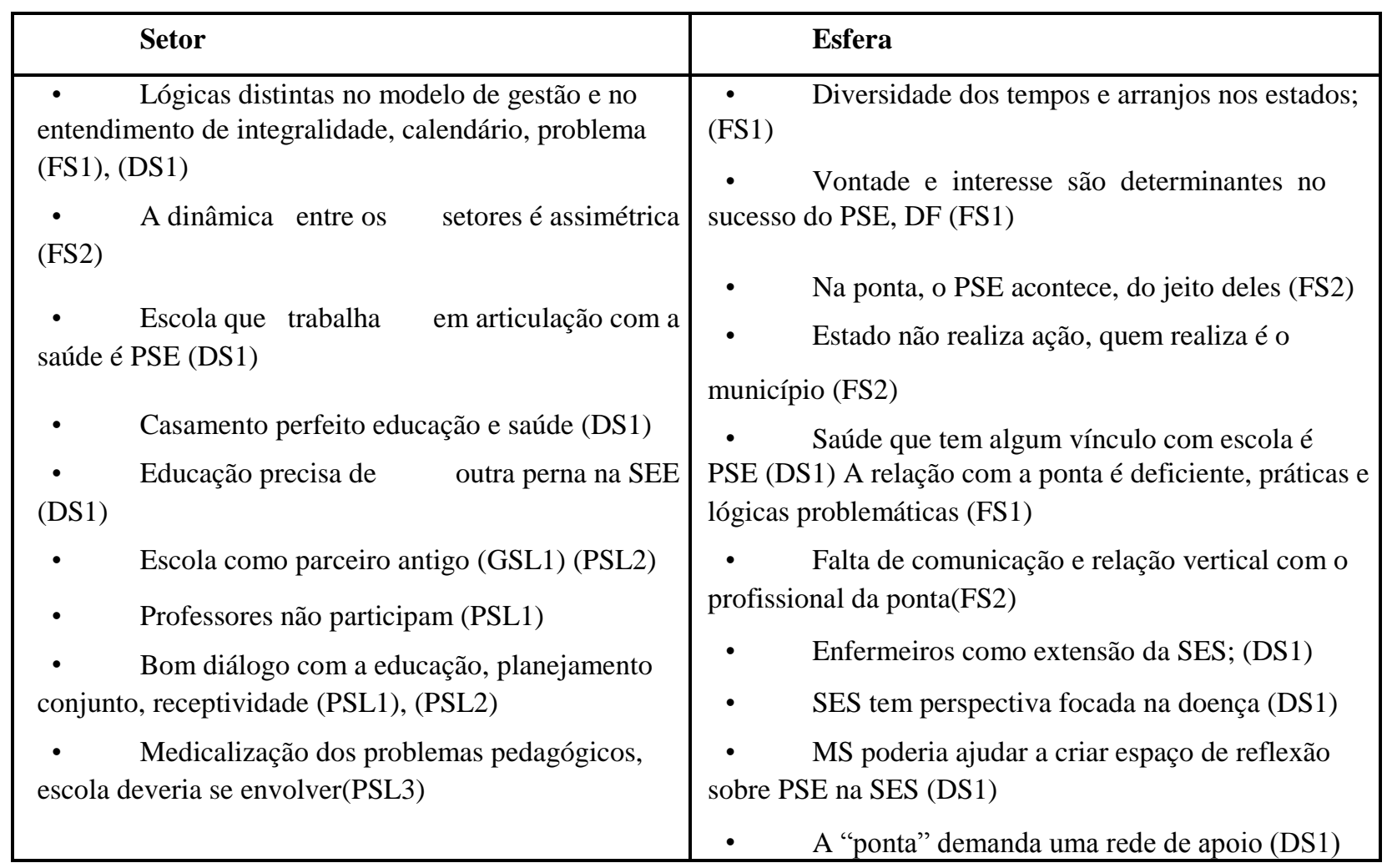

.Fonte: Entrevistas aplicadas aos participantes do Programa Saúde na Escola.

No que se refere ao setor, de uma maneira geral, a educação é reconhecida como parceiro potencial e fundamental, mesmo quando é colocado somente como setor demandante de ações pontuais ou quando há criticas em relação à participação dos professores, sobretudo na perspectiva da gestão local. Entre as esferas, foi ressaltado o desafio de integração entre gestão e execução apontando a comunicação e a verticalidade unidirecional das relações como pontos a serem melhorados.

\subsection{Como os atores da Educação percebem o Outro setor ou esfera no Programa?}

O quadro abaixo apresenta a percepção dos atores do setor educação com relação ao setor saúde e também com relação às demais esferas do PSE, na educação. 
Quadro 5 -Percepções dos atores da educação sobre o Outro setor ou esfera no Programa

\begin{tabular}{|c|c|}
\hline Setor & Esfera \\
\hline $\begin{array}{l}\text { • É a saúde que responde pela demanda que precisa do } \\
\text { atendimento (DE1); } \\
\text { • } \quad \text { Lógica diferente: na saúde o interlocutor varia na } \\
\text { regional, na educação é sempre o mesmo (DE1) } \\
\text { • } \quad \text { A saúde precisa chamar outras áreas para compor o } \\
\text { GTI e apoiar o PSE, pois as ações são fragmentadas em relação } \\
\text { aos ciclos de vida (DE1) } \\
\text { • } \quad \text { Trabalhar de forma intersetorial não acontece por } \\
\text { imposição, há distanciamento entre as áreas, precisa trabalhar } \\
\text { com quem tem interesse (DE1) } \\
\text { • } \quad \text { A saúde toma a frente na semana da saúde (PEL1) } \\
\text { - } \quad \text { Bom atendimento da saúde no CS e na escola (PEL1) } \\
\text { • } \quad \text { Falta de retorno da saúde (GEL2) }\end{array}$ & $\begin{array}{l}\text { • Nas regionais de ensino a gerência de } \\
\text { infraestrutura e apoio educacional executa as } \\
\text { ações; (DE1) } \\
\text { • } \\
\begin{array}{l}\text { (DE1) } \\
\text { - }\end{array} \text { Desafio na Esfera federal é recompor a } \\
\text { equipe do PSE no MEC (DE1) } \\
\text { - } \quad \text { Escola deve incluir o PSE no PPP e } \\
\text { buscar parceiros para melhorar viés pedagógico } \\
\text { (DE1) }\end{array}$ \\
\hline
\end{tabular}

Fonte: Entrevistas aplicadas aos participantes do Programa Saúde na Escola.

Em relação à perspectiva que a educação tem da saúde, destaca-se que esta ultima é percebida como um parceiro pontual, que se utiliza do espaço da escola para trabalhar demandas diversas e que ocupa a escola em determinadas datas temáticas. A queixa em relação à falta de retorno por parte da saúde indica insatisfação na relação como o setor. $\mathrm{Na}$ relação entre as esferas da educação, há um sentimento de falta de suporte para o Programa na gestão local e uma preocupação em reorganizar o setor para se trabalhar o PSE.

\subsection{Percepção de atores sobre a relação com o Outro no PSE}

Ao serem indagados sobre como percebem a implementação do programa, os gestores e os profissionais das três esferas e dois setores revelaram, nas suas respostas, elementos de como percebem as atribuições de seus parceiros, categorizados como o "outro". Como apresentadas nos quadros 4 e 5 acima, as falas exprimem preocupações ora com as relações verticais do programa, ora com as articulações entre os setores envolvidos. Algumas vezes, tais preocupações podem atravessar as relações setoriais nas diferentes esferas, sugerindo a variedade de arranjos e formas de articular setores e esferas dentro do programa. O diagrama 1, abaixo, representa a tendência na prevalência do foco de preocupação dos informantes considerando as dimensões verticalidade (esferas) e relação entre setores (horizontalidade ou transversalidade) segundo a atuação do informante na esfera federal, distrital ou local. A forma de pirâmide enfatiza a situação de proximidade do informante ou com a gestão federal (ponta da pirâmide) ou com a base (atuação local) 
Figura 1: Representação do foco de preocupação dos atores segundo a esfera de atuação

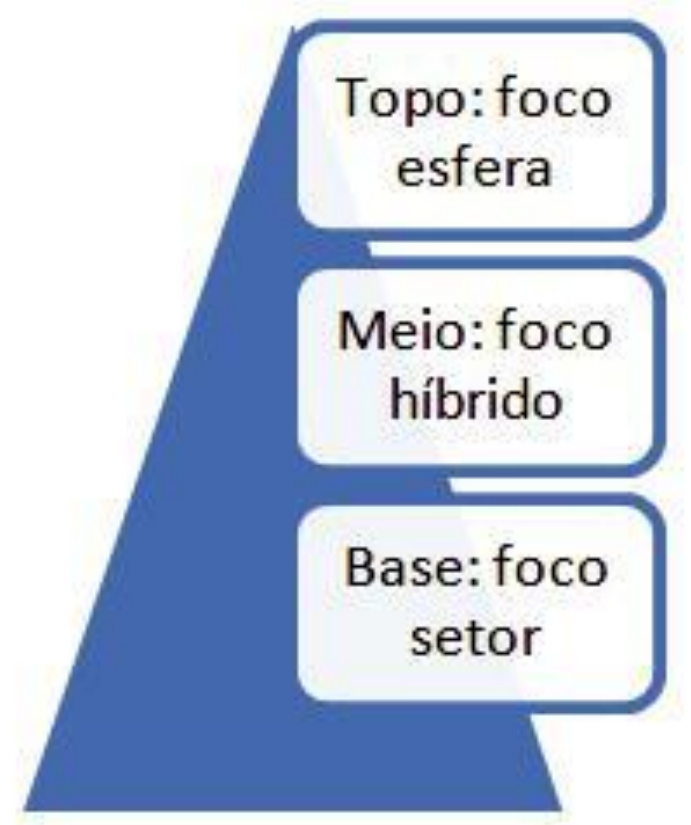

Foi feita a aferição do número de respostas sobre a "percepção do outro no programa" expressas nos quadros 4 e 5, considerando as variáveis "o foco de preocupação" (setor e esfera) e a "posição de atuação do informante" (esfera federal, distrital ou local). A posição de atuação do informante consta da identificação de cada entrevistado por meio de códigos, onde F se refere à esfera federal, D distrital e L local. (códigos de identificação das respostas). Assim, é possível conferir a quantidade de respostas referentes ao setor ou à esfera nos quadros 4 e 5 analisados.É possível sugerir, no campo da saúde (quadro 4) dentre aqueles que expressaram preocupações com relação ao "setor" (a relação entre o setor saúde e a educação) que a maioria era composta por profissionais ou gestores da esfera local (6 dentre doze afirmações), seguidos pelos distritais (4 dentre 12 afirmações).

Foram duas as preocupações com referência às relações entre os setores no âmbito federal, uma que apontava "lógicas distintas no modelo gestão e no entendimento de integralidade, calendário" (FS1) e outra que afirmava haver dissimetria na dinâmica entre educação e saúde (FS2). Na coluna das preocupações relativas à esfera, foram seis afirmações provenientes da esfera federal, cinco da distrital e nenhuma local.

No campo da educação, (quadro 5) foram quatro afirmações dentre sete, da esfera distrital, com foco no setor. Dentre as preocupações do campo educacional com as relações verticais (esfera) todas as quatros foram provenientes de gestores distritais, sugerindo tendência à maior preocupação com as relações entre os setores junto aos atores locais. 


\section{A percepção global do $\mathrm{PSE}$}

Na esfera federal, o PSE é percebido, pelo setor saúde, como formalmente instituído, com avanços na gestão (sugerindo continuidade do programa no setor e na esfera) e capacidade de propor mudanças "momento de avaliação e redesenho" (FS2), sugerindo ser esta esfera (federal) e setor (saúde), aqueles com maior poder de decisão e liderança nos espaços de governança do programa. Neste sentido, o PSE parece ainda caracterizar-se por um desenho verticalizado, de cima para baixo (top down) (4) e assimétrico na distribuição de poder entre os setores. A "centralidade na tomada de decisões" foi igualmente percebida por gestores como desafio para o trabalho intersetorial no PSE (12):

Outro elemento citado pelos entrevistados tanto da saúde quanto da educação, nas esferas federal e distrital, foi o potencial do programa em promover a articulação intrasetorial (sugerindo o potencial do PSE em gerar mudanças consideradas positivas). A intersetorialidade desencadeia uma nova forma de planejar e realizar ações e serviços (13). Desta forma, é como se a articulação com um outro setor - a educação- acabasse por exigir novas condutas internas e outros modos de organização para o setor saúde. Este efeito articulador do PSE foi mencionado por uma gestora distrital da educação que sinalizou, com relação à composição dos GTI, a fragmentação da saúde na sua estrutura interna, implicando que muitas secretarias ou diretorias deveriam compor o GTI para que se pudesse atuar articulada e integralmente na proposição de ações de saúde na escola.

Outro aspecto positivo do percebido foi o poder de articulação programática do PSE, que para gestores distritais da saúde "alinha ações entre programas já existentes na secretaria", sugerindo que o programa é facilmente integrado às ações em curso e que corresponde às ações finalísticas do setor/esfera. Para os atores da saúde, o PSE pode ser facilmente integrado na atenção básica por corresponder a pautas e necessidades setoriais desta área.

Oferece, em particular, a oportunidade de ampliar a cobertura das ações de atenção à saúde dos jovens, incluindo o espaço escolar nos territórios de abrangência das equipes de Saúde da Família.

Fragmento da entrevistas com o sujeito (DS1): “ (...) vejo o PSE em termos de integração, um cuidado à saúde do aluno (...) vem dar resposta em termos do cuidado com os jovens (...) é esse acompanhamento que é importante para a atenção integral”.

Neste mesmo sentido, encontram-se achados de estudo sobre a relação da estratégia de saúde da família com a intersetorialidade (13) que dentre as ações intersetorias mais frequentemente declaradas por profissionais da atenção básica, encontra-se o PSE. "A singularidade do PSE é ter sido implementado segundo o modelo brasileiro de atenção primária à saúde" (14).

O programa responde à necessidade de ampliar a relação da Estratégia Saúde da Família com os projetos de Promoção da Saúde e, em particular, com o jovem: 
A relação entre os adolescentes e os profissionais de saúde ainda é limitada, sendo a proposta do PSE uma oportunidade para estabelecer e

$228 / /$

manter um vínculo pautado na corresponsabilização e em uma postura de confiança entre adolescentes e ESF (15).

O gestor distrital responsável pelo PSE no setor educação ratificou a correspondência positiva do programa com a lógica e a finalidade do serviço onde este foi implantado - a subsecretaria de infraestrutura e apoio educacional- e salientou o potencial para a mudança positiva no serviço e no setor devido à capacidade do PSE de promover a articulação intrasetorial.

Neste caso, a articulação com a Subsecretaria de Educação Básica, percebida como necessária para que o programa ganhe a centralidade dos conteúdos e práticas a serem negociados na construção do Projeto Político Pedagógico da escola. “(...) lá dentro (da sala de aula) a gente (infraestrutura) não entra, nós não temos a competência de estabelecer um PSE dentro do Projeto Político Pedagógico da escola (...)" (DE1). A localização do PSE na Subsecretaria de Infraestrutura e Apoio Educacional reflete o modelo da "saúde do escolar", onde a escola, percebida como "agente terapêutico" (16).

Vigiava e promovia o saneamento do ambiente escolar, dotando-se de equipamentos e profissionais para monitorar e cuidar da saúde bucal, oftalmológica e nutricional dos seus alunos (17). O Programa Saúde do Escolar existe na Secretaria de educação do DF desde 1978, na época, contava, inclusive, com clínicas odontológicas. Assim, o PSE foi naturalmente encaminhado para esta área da Secretaria, que segundo a gestora "corresponde à "área fim” da gerência".

\section{Percepção sobre os componentes do Programa}

A percepção dos atores sobre os componentes do programa sugere a existência de territórios de competência partilhados entre os setores. Os profissionais e gestores da saúde distritais e locais tendem a considerar o componente I como de fácil execução.

Fragmento da entrevistas com o sujeito (DS1): “ (...) dentro do componente 1, uma ação que acontece a rodo sem muito envolvimento da gente aqui da gestão são as medidas antropométricas. $\mathrm{O}$ TAV, teste de acuidade visual, tá ficando cada vez mais comum, era uma demanda que já acontecia (...) agora a gente tá conseguindo ampliar”.

Para os profissionais da educação, o componente II constituiria a oportunidade de integrar os conteúdos temáticos da saúde no Projeto Político Pedagógico das escolas, entendo este como o componente "voltado para a educação". Entretanto, ao falar do componente 1, a gestora da educação ressente que à educação não "cabem ações substantivas", sugerindo o protagonismo da saúde que "quando chega lá, no momento que enxergamos a demanda, que precisa de atendimento, continua sendo a saúde (...), a educação não tem um viés clínico (...)" (DE1). No fundo, parece que os 
gestores, mesmo ao afirmarem a importância das ações de prevenção e promoção, estas atribuídas à educação, continuam a valorizar a assistência e as ações clínicas como aquelas de fato substantivas e resolutivas, em contraposição ao modelo de promoção da saúde proposto pelo PSE.

\section{Sobre a institucionalidade do PSE no DF}

No que toca a institucionalidade do programa, os gestores distritais de ambos os setores valorizam a importância da formalização dos Grupos de Trabalho Intersetoriais, e se percebe que estes representam espaços essenciais para o fazer articulado entre setores e esferas. O GTI funciona não apenas como operador técnico do planejamento das ações, monitoramento, mobilização, formação, mas também como espaço político de negociação, afirmação e reconhecimento do programa. Na esfera federal, assim como na distrital, foi identificada a formalização do Programa dentro de cada setor, com a atribuição de um locus na organização e um responsável "oficial” para operar o PSE.

Não foi encontrada indicação de descontinuidade dentro dos órgãos responsáveis pela implementação no nível distrital e na saúde federal. Entretanto, no DF, o GTI permanece informal, embora funcione ativamente.

A dificuldade em formalizar o GTI é atribuída, pelos gestores, à instabilidade política, citando várias mudanças internas nas secretarias de Educação e Saúde. Quanto à esfera local, a percepção dos profissionais sugere pouca formalização, onde foi expressa a demanda de se estabelecer um "setor exclusivo" (GEL2). A despeito da formalização do GTI, o PSE parece contar, no Distrito Federal, com uma rede informal de profissionais de setores variados remanescente de programas e projetos anteriores, em particular o Saúde e Prevenção nas Escolas (SPE) que participam de ações pontuais quando mobilizados.

Por outro lado, os profissionais que atuam diretamente na operação cotidiana do programa, declaram sofrer com um acúmulo de tarefas, além de, na maioria das vezes, não contar com um trabalho em equipe para a execução das metas do programa. As falas presentes na percepção destes atores sobre o PSE sinalizaram um "Trabalho solitário, euquipe", ou ainda enfatizaram a importância do planejamento setorial, pois “(...) sair do Centro de Saúde é difícil” (PSL1). O acúmulo de tarefas e a sobrecarga de trabalho junto ao nível local foram igualmente mencionados em relato sobre a implementação do PSE em Fortaleza, onde tanto os professores como os profissionais das ESF, “apresentavam-se ansiosos acerca da possibilidade de não cumprimento das ações programadas, devido ao acúmulo de tarefas rotineiras." (15)

Finalmente, foi significativo o efeito positivo do PROVAB, percebido por gestores e profissionais da saúde e da educação como uma ajuda essencial para cumprimento de metas. Tal colocação ratifica a importância de ações que afirmem a importância do programa, com investimentos em recursos humanos para o PSE. 


\section{CONCLUSÃO}

A análise das percepções dos gestores e profissionais atuantes no PSE trouxe importantes informações a respeito da forma como este programa é vivenciado e construído no cotidiano. De acordo com os dados apresentados, nota-se que o programa é percebido de forma diferente pelos atores da esfera federal, distrital e local. A maior diversidade na percepção de como o programa está instituído é observada entre as esferas federal e local, ficando a distrital em situação híbrida onde partilha percepções com as demais esferas.

Igualmente, constatou-se a percepção do protagonismo e da assimetria dos papeis entre os setores, onde a primazia percebida foi do setor saúde. Em ambos os setores, em todas as esferas, mas, particularmente na ponta onde as ações são realizadas, percebeu-se que o Programa ocupa um espaço fronteiriço, onde parece não constituir prioridade nem para a educação, nem para a saúde.

Também foi enfatizado como desafio, aumentar a interlocução entre os profissionais da gestão distrital e os locais. Parece existir uma desconexão que se manifesta, inclusive, na distância entre adesão formal ao programa e atividades realmente executadas. Tal incongruência pode refletir a verticalidade e centralidade hierarquizada do processo de adesão ao PSE, sugerindo a importância de se propor estratégias de comunicação mais dialógicas, com ênfase na participação, entre as esferas do programa.

Finalmente, o estudo sugere a importância de programas como o PSE na dinâmica de transformação da cultura organizacional do Estado, principalmente nos espaços da gestão federal e distrital. O reconhecimento do potencial de articulação intrasetorial do PSE amplia a compreensão das potencialidades das iniciativas de gestão intersetorial.

Considera-se que foram respondidas as questões preliminares desta pesquisa. Os achados agregam elementos à compreensão da implementação cotidiana do Programa Saúde na Escola, apontando pistas para novos estudos e ratificando o interesse das pesquisas qualitativas para o entendimento das formas de racionalidade que movem os participantes de um programa.

\section{REFERÊNCIAS BIBLIOGRÁFICAS}

1. BUSS, P., M., Promoção da Saúde da Família, Promoção da Saúde, Programa saúde da Família, dezembro de 2002. p. 50-63.

2. Ferreira IRC, Ramos V D S, Jorge, M S, Tetu, M S. Diplomas Normativos do Programa Saúde na Escola: análise de conteúdo associada à ferramenta. Ciênc. saúde coletiva 2012, Dez. [Acesso em 13.oct.2015]

3. Figueiredo T A M, Machado V L T, Abreu M Mi S. A saúde na escola: um breve resgate histórico. Ciênc. saúde coletiva, 2010 15( 2 ): 397-402.

4. Silva, C., S., Promoção da saúde na escola: Modelos Teóricos e desafios da 
Intersetorialidade no município do Rio de janeiro, Tese de Doutorado, Escola Nacional de Saúde Pública Sérgio Arouca, Rio de janeiro, sn., 2010, $198 \mathrm{f}$.

$231 / /$

5. Silva Junior, A J. Programa saúde na escola: limites e possibilidades intersetoriais. Interface (Botucatu), 2014, 18( 51 ): 799-799.

6. Lourau, R., L’analyse institutionnelle, Paris: Les èditions de Minuit, 1970: 102.

7. Potvin, L. On the nature of programs: health promotion programs as action. Ciência e Saúde Coletiva, Sept 2004, 9 (3): 731-738

8. Bodstein, R. O debate sobre avaliação das práticas e estratégicas em Promoção da saúde. B. Téc. Senac: a R. Educ. Prof., Rio de Janeiro, 2009, 35 (2): 7-15.

9. Minayo, (organizadora), Deslandes, Neto, Gomes, Pesquisa social, teoria, método e criatividade. $18^{\mathrm{a}}$ edição, Petrópolis: RJ: Vozes, 2001: 22-23.

10. Gil, A.C., Métodos e Técnicas de Pesquisa Social, São Paulo: Atlas, 2014: 94

11. World Health Association. Division of Mental Health. Qualitative Research for Health Programmes. Geneva: WHA, 1994.

12. Bardin, L. Análise de conteúdo. Lisboa: Edições 70, 1995.

13. Ferreira, I.R.C.; Vosgerau, D.S.A.R; Moysés, S.J; Moysés, S.T.; Diplomas Normativos do Programa Saúde na escola: análise de conteúdo associada à ferramenta ATLAS TI, Ciência e Saúde Coletiva, 17 (12):3385-3398, 2012,

14. Araújo Dias, M S; Feijão Parente, J R; Osawa Vasconcelos, M I; Cavalcante Dias, F A. Intersetorialidade e estratégia Saúde da Família: tudo ou quase nada a ver? Ciência \& Saúde Coletiva, 2014,19 (11): 4371-4382

15. Mendonça, C S. [Entrevistas]. Revista Brasileira Saúde da Família, Brasília, DF. 2008, 20: $6-7$

16. Santiago L M, Rodrigues M T P, Oliveira Junior A D, Moreira TMM. Implantação do Programa Saúde na escola em Fortaleza-CE: atuação de equipe da Estratégia Saúde da Família. Rev. bras. enferm. 2012,65( 6 ): 1026-1029

17. Canesqui, A. M. Trajetória da educação popular nas instituições estaduais de saúde. In: Paiva, V. (Org.). Perspectivas e dilemas da educação popular. Rio de Janeiro: Graal, 1984:315-24.

18. Mohr, A. e Schall, V. T. Rumos da educação e saúde no Brasil e sua relação com a educação ambiental. In: Cadernos de Saúde Pública, 1992, 8 (2): 199-203. 
19. Collares, C A L; Moysés, M A A. Educação ou Saúde? Educação X Saúde? Educação e Saúde! Cadernos Cedes, 1985, 15: 7-16..

Artigo apresentado em 11-11-14

Artigo aprovado em 23-05-15

Artigo publicado no sistema em 22-12-15 